\title{
Nutech Functional Score (NFS), a New Scoring System to Assess the Level of Impairment in Patients with Cerebral Palsy

\section{Abstract}

Background: A non-progressive disorder cerebral palsy (CP) occurs as a result of the damage to the brain of a fetus and newborns. It is estimated to affect every one in 323 children in the U.S. The Gross Motor Function Classification System (GMFCS) has been a validated and reliable tool used for assessing the gross motor function in patients with CP. However the use of tool has been found to be limited in assessing certain symptoms of CP that are essential to be evaluated. Our study aimed at developing a scoring system that can assess the symptoms which remained untouched in GMFCS.

Methods and Findings: We initiated compiling the lists of symptoms from the diagnostic records of the cases who visited our facility. CP patient who were previously assessed with GMFCS, were then assessed using Nutech Function Score (NFS), the new scoring system. NFS is a 32 point positional and directional scoring system that can assess the CP symptoms that remain far from assessment in GMFCS; these symptoms are feeding, indication, epilepsy, toilet training, drooling, mathematical skills, hearing, vision, commands, smiling, constipation, recognition/awareness, eye contact, aggression, speech, breathing difficulty, defense mechanism and swallowing. As opposed to GMFCS, NFS scoring system can be used to assess patients aged above 18 years. We have also converted the scores into numeric grades.

Conclusion: NFS appears to be a unique tool that can be used globally to assess the improvement in patients with $C P$.

\section{Keywords}

Cerebral Palsy; Nutech Functional Score; Patient assessment; Scoring system, GMFCS.

\section{Geeta Shroff',} J.K Bharthakur ${ }^{2}$

1 Director, Nutech Mediworld, New Delhi, India.

2 Retired Additional Secretary, Ministry of Home Affairs, Government of India.

Contact information:

\section{Geeta Shroff.}

Address: Nutech Mediworld, H-8, Green Park Extension, New Delhi-110016.

Tel: (91) 1126180039.

Fax: (91) 1126560089

$\equiv$ geetashroff@hotmail.com 


\section{Introduction}

Cerebral palsy (CP) is a devastating group of nonprogressive movement and posture related disorders that most commonly affect children. It occurs as a result of the damage to the brain of a fetus and newborns. [1] According to the estimation by the Centers of Disease Control (CDC) in the U.S., every one in 323 children is affected by CP. [2] The movement disorders that might occur in the CP patients are; spasticity (stiff muscles), dyskinesia (uncontrollable movements) and ataxia (poor balance and coordination). Based on the type of movement disorder involved, CP has been divided into four types which include spastic CP, dyskinetic CP (choreoathetoid, athetoid, and dystonic cerebral palsies), ataxic CP and mixed CP. Spastic CP, the most common form of $C P$, affects around $80 \%$ of people with CP. [3]

Several scoring systems have been developed that aimed to assess the level and extent of impairment in patients with $\mathrm{CP}$ including the Gross Motor Function Classification System (GMFCS), the Manual Ability Classification System (MACS) and Bimanual Fine Function (BFMF). [4-6] Both GMFCS and MACS tools have been used internationally. Previous studies have shown them to be valid and reliable. $[6,7]$

This paper will reflect on the presently used GMFCS scoring system. GMFCS classifies the gross motor function in patients with CP based on selfinitiated movement; especially their ability to walk and stand. [8]. However, evaluation of a patient with CP using GMFCS poses certain limitations. Firstly, it does not assess certain parameters that are essential to be evaluated in the patients with CP which include epilepsy, hearing, drooling, writing, mathematical skills, communicating and playing. (Figure 1) Secondly, distinction between first two levels of GMFCS is unclear, mainly for children below the age of 2 years. [8] Thirdly, the scoring is not numeric, i.e., we cannot add or subtract the grades.
Our facility has been treating patients with $\mathrm{CP}$ since 2000. While grading the CP patients with GMFCS scoring system, the doctors felt it difficult to grade several parameters. This led to the development of Nutech Functional Score (NFS), a new scoring system, in 2004. The new scoring system called NFS is a numeric scale that scores almost all the known symptoms for patients with CP. Several parameters are assessed in NFS, but are not included in GMFCS. However, these parameters are essential to be assessed in CP patients. Figure 1

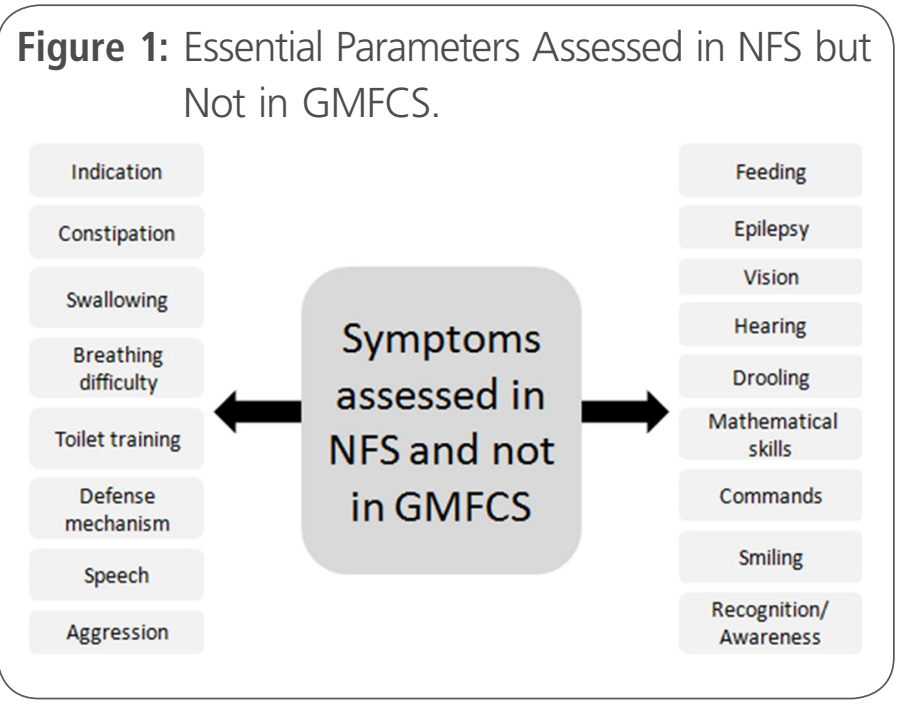

The paper will discuss about the development of NFS and will compare it with the GMFCS, an internationally used scoring system.

\section{Methods}

The study included CP patients who visited our facility either with the previous diagnosis of the condition or were diagnosed at the institute by routine medical procedure for the diagnosis. Both, common or rare symptoms of the condition with which the patient was evaluated were documented in the diagnostic history. In 2004, the institution started compiling the lists of symptoms from the diagnostic records of the cases. Thus, the patient can be evaluated based on the list of symptoms. These lists are continuously revised to maintain the accuracy. 
A symptom is evaluated based on five ordinal grades running in BAD $\rightarrow$ GOOD direction. We used NFS, the new scoring system, to assess CP patients who were previously assessed with GMFCS. We have converted the grades into numeric values required for probability based studies.

\section{Results}

We have developed a 32 point positional and directional scoring system that assesses the patients with CP. It covers all the known symptoms of a patient with $C P$ that are important to assess the patient with CP. These symptoms include feeding, epilepsy, indication, toilet training, mathematical skills, drooling, hearing, vision, commands, smiling, recognition/awareness, constipation, eye contact, aggression, speech, defense mechanism, breathing difficulty and swallowing. The symptoms along with their grades are presented in Appendix 1. However, if the symptoms were found not to be associated with the ailment, they were graded as not afflicted ailment (NAA). If any of the patients was too young to respond to the diagnosis of symptom then it was graded as too young to elicit (TYE).

Appendix 1. Nutech Functional Score-Cerebral Palsy (As on 11 July 2013).

\begin{tabular}{|c|c|c|}
\hline \multirow{2}{*}{ Parameter } & Description & Score \\
\hline & Not Afflicted & NAA \\
\hline \multicolumn{3}{|l|}{ Epilepsy } \\
\hline & Multiple times/ day & 1 \\
\hline & 1-2 times/ day & 2 \\
\hline & 1-2 times/ alternative day & 3 \\
\hline & 1-2 times/ week or occasionally & 4 \\
\hline & Less frequent than in 4 & 5 \\
\hline \multicolumn{3}{|l|}{ Vision } \\
\hline & Blind & 1 \\
\hline & PL plus & 2 \\
\hline & Figures out but blurred & 3 \\
\hline & Vision up to 25 centimeters & 4 \\
\hline & Vision > 25 centimeters & 5 \\
\hline
\end{tabular}

\begin{tabular}{|c|c|c|}
\hline \multirow{2}{*}{ Parameter } & Description & Score \\
\hline & Not Afflicted & NAA \\
\hline \multicolumn{3}{|l|}{ Hearing } \\
\hline & No hearing & 1 \\
\hline & Can hear with source close to ear & 2 \\
\hline & Only loud noise from three meters & 3 \\
\hline & Only loud noise from ten meters & 4 \\
\hline & Hearing $>10$ meters & 5 \\
\hline \multicolumn{3}{|l|}{ Drooling } \\
\hline & Constant Drooling & 1 \\
\hline & Drools only during the day & 2 \\
\hline & Drooling 4-5 times a day & 3 \\
\hline & Drooling Controlled ( $1-2$ times a day) & 4 \\
\hline & Drooling less than $1-2$ times a day & 5 \\
\hline \multicolumn{3}{|l|}{ Writing } \\
\hline & Too Young to Elicit & TYE \\
\hline & Cannot write & 1 \\
\hline & Only single alphabet & 2 \\
\hline & Single word & 3 \\
\hline & Few words but no sentences & 4 \\
\hline & Writing better than in grade 4 & 5 \\
\hline \multicolumn{3}{|c|}{ Mathematical skills } \\
\hline & Too Young to Elicit & TYE \\
\hline & No capability to solve problem & 1 \\
\hline & Very simple with Basic & 2 \\
\hline & Addition \& Subtraction & 3 \\
\hline & Addition, Subtraction \& Multiplication & 4 \\
\hline & Problem solving better than in grade 4 & 5 \\
\hline \multicolumn{3}{|l|}{ Commands } \\
\hline & Too Young to Elicit & TYE \\
\hline & Does not follow at all & 1 \\
\hline & Initiates but do not complete & 2 \\
\hline & Follow commands & 3 \\
\hline & Follow group commands & 4 \\
\hline & $\begin{array}{l}\text { Command following better than in } \\
\text { grade } 4\end{array}$ & 5 \\
\hline \multicolumn{3}{|l|}{ Smiling } \\
\hline & Too Young to Elicit & TYE \\
\hline & No Smiling & 1 \\
\hline & Smiles only at parents & 2 \\
\hline & Smiles only at relatives & 3 \\
\hline & Smiles when called by name & 4 \\
\hline & $\begin{array}{l}\text { Smiling more congenital than in } \\
\text { grade } 4\end{array}$ & 5 \\
\hline
\end{tabular}




\begin{tabular}{|c|c|c|}
\hline \multirow{2}{*}{ Parameter } & Description & Score \\
\hline & Not Afflicted & NAA \\
\hline \multicolumn{3}{|c|}{ Recognition/Awareness } \\
\hline & Too Young to Elicit & TYE \\
\hline & Does not recognize & 1 \\
\hline & Only parents & 2 \\
\hline & Parents and Relatives & 3 \\
\hline & By name & 4 \\
\hline & $\begin{array}{l}\text { Recognition/ Awareness more intimate } \\
\text { than in grade } 4\end{array}$ & 5 \\
\hline \multicolumn{3}{|l|}{ Eye Contact } \\
\hline & Too Young to Elicit & TYE \\
\hline & No eye contact at all & 1 \\
\hline & Eye contact fleetingly & 2 \\
\hline & Eye contact with known people & 3 \\
\hline & Eye contact on calling by name & 4 \\
\hline & Eye contact bolder than in grade 4 & 5 \\
\hline \multicolumn{3}{|l|}{ Aggression } \\
\hline & Too Young to Elicit & TYE \\
\hline & All the time & 1 \\
\hline & Only during day time & 2 \\
\hline & When woken up hungry or tired & 3 \\
\hline & Only once a day & 4 \\
\hline & Aggression more relented than in grade 4 & 5 \\
\hline \multicolumn{3}{|l|}{ Speech } \\
\hline & Too Young to Elicit & TYE \\
\hline & Non verbal & 1 \\
\hline & Babbling & 2 \\
\hline & Formation of one word at a time & 3 \\
\hline & $\begin{array}{l}\text { Formation of many words but no } \\
\text { sentences }\end{array}$ & 4 \\
\hline & More fluent than in grade 4 & 5 \\
\hline \multicolumn{3}{|l|}{ I T Skills } \\
\hline & Too Young to Elicit & TYE \\
\hline & None & 1 \\
\hline & Mouse control & 2 \\
\hline & Mc plus sound discrimination & 3 \\
\hline & Mc plus sound discrimination plus colors & 4 \\
\hline & $\begin{array}{l}\text { Color, sound and mouse control better } \\
\text { than in grade } 4\end{array}$ & 5 \\
\hline \multicolumn{3}{|l|}{ Indication } \\
\hline & No indication & 1 \\
\hline & Only basic needs (wetting, hunger, pain) & 2 \\
\hline & $\begin{array}{l}\text { Indicates anger/fear/happiness } \\
\text { (Emotional) }\end{array}$ & 3 \\
\hline & Indicates few words & 4 \\
\hline & Indication better than in grade 4 & 5 \\
\hline & $\begin{array}{l}\text { Smiling more congenital than in } \\
\text { grade } 4\end{array}$ & 5 \\
\hline
\end{tabular}

\begin{tabular}{c|c|c|}
\multirow{3}{*}{ Parameter } & Description & Score \\
\cline { 2 - 3 } & Not Afflicted & NAA
\end{tabular}

Feeding

Peg tubes

Can be fed liquids only after coaxing 2

Can be fed liquids and solids after coaxing

Can be fed liquids and solids without coaxing

Feeding problem better than in grade $4 \quad 5$

Smiling more congenital than in grade 4

\begin{tabular}{l|l} 
Smiling more congenital than in \\
grade 4
\end{tabular}

Toilet Training

\begin{tabular}{|l|c|}
\hline Too Young to Elicit & TYE \\
\hline No indication at all & 1 \\
\hline Can indicate bowel occ. & 2 \\
\hline Can indicate bowel and bladder occur. & 3 \\
\hline Can indicate bowel and bladder all time & 4 \\
\hline $\begin{array}{l}\text { Toilet training problem better than in } \\
\text { grade 4 }\end{array}$ & 5 \\
\hline
\end{tabular}

Daily Living Skills

Too Young to Elicit

TYE

Totally dependent

1

Can initiate but needs help

Can initiate and complete task imperfectly

2

Can initiate and complete task almost correctly

Daily living skills better than in grade $4 \quad 5$

Defense Mechanism

Absent according to age

1

Present by retrospect crying 2

Present by anticipating and response when stimulus is seen

Present by anticipating without seeing stimulus

Defense mechanism better than in grade 4

5

Breathing Difficulty

On external support

Short Shallow pattern (RR/ Min) 2

Tachypnoea (RR - Above 40/ Minute) 3

Tachypnoea (RR - Above 30-40/ Minute) 4

Breathing pattern better than in grade $4 \quad 5$

Swallowing

Constant swallowing problem 1

Only liquid 2

Liquid \& semi liquid 3

Solids with difficulty 4

Swallowing better than in grade $4 \quad 5$

This article is available at: www.intarchmed.com and www.medbrary.com 


\begin{tabular}{|c|c|c|}
\hline \multirow{2}{*}{ Parameter } & Description & Score \\
\hline & Not Afflicted & NAA \\
\hline \multicolumn{3}{|l|}{ Constipation } \\
\hline & 4 per week & 1 \\
\hline & 3 per week & 2 \\
\hline & 2 per week & 3 \\
\hline & 1 per week & 4 \\
\hline & $\begin{array}{l}\text { Constipation problem better than in } \\
\text { grade } 4\end{array}$ & 5 \\
\hline \multicolumn{3}{|c|}{ Head Control } \\
\hline & Too Young to Elicit & TYE \\
\hline & No control & 1 \\
\hline & Initiating but not complete & 2 \\
\hline & Completing but not holding & 3 \\
\hline & Holding minimal support & 4 \\
\hline & Head control better than in grade 4 & 5 \\
\hline \multicolumn{3}{|c|}{ Trunk Control } \\
\hline & Too Young to Elicit & TYE \\
\hline & No control & 1 \\
\hline & $\begin{array}{l}\text { Can initiate trunk control with } \\
\text { maximum support }\end{array}$ & 2 \\
\hline & $\begin{array}{l}\text { Can initiate and hold the trunk below } \\
\text { two minutes }\end{array}$ & 3 \\
\hline & $\begin{array}{l}\text { Can initiate and hold the trunk above } \\
\text { without upper body swinging }\end{array}$ & 4 \\
\hline & Trunk control better than in grade 4 & 5 \\
\hline \multicolumn{3}{|l|}{ Rolling over } \\
\hline & Too Young to Elicit & TYE \\
\hline & Can not initiate & 1 \\
\hline & Initiates but cannot take full turn & 2 \\
\hline & Initiates, take turn but cannot hold & 3 \\
\hline & $\begin{array}{l}\text { Initiates, take turn but hold below five } \\
\text { minutes }\end{array}$ & 4 \\
\hline & Rolling over better than in grade 4 & 5 \\
\hline \multicolumn{3}{|l|}{ Crawling } \\
\hline & Too Young to Elicit & TYE \\
\hline & Cannot even get into position & 1 \\
\hline & Can get into position only & 2 \\
\hline & $\begin{array}{l}\text { Can use legs forward with support of } \\
\text { trunk }\end{array}$ & 3 \\
\hline & $\begin{array}{l}\text { Can use both legs without much } \\
\text { support of trunks }\end{array}$ & 4 \\
\hline & Crawling better than in grade 4 & 5 \\
\hline \multicolumn{3}{|l|}{ Sitting } \\
\hline & Too Young to Elicit & TYE \\
\hline & Can not sit & 1 \\
\hline & Sitting with full trunk support & 2 \\
\hline & Sitting with less trunk support & 3 \\
\hline & Sitting with minimal trunk support & 4 \\
\hline & Sitting better than in grade 4 & 5 \\
\hline
\end{tabular}

\begin{tabular}{c|c|c|}
\multirow{2}{*}{ Parameter } & Description & Score \\
\cline { 2 - 3 } & Not Afflicted & NAA \\
\hline
\end{tabular}

Standing

Too Young to Elicit

TYE

Cannot stand

1

Can push hip up with hand support

Can stand with full caliper and chest trunk support

Can stand with half caliper and without much of chest support

Standing better than in grade 4

Standing better than in grade $4 \quad 5$

Kyphosis

\begin{tabular}{|l|l|}
\hline Kyphosis present & 1 \\
Kyphosis lessered & 5
\end{tabular}

\section{Scoliosis}

Scoliosis present

1

Scoliosis lessered

\section{Walking}

Too Young to Elicit

TYE

No walking

Walking with full caliper and full

support

Walking with full caliper and only walker

Walking with knee caliper and walker 4

Walking better than in grade 4

5

\section{Climbing stairs}

Too Young to Elicit

TYE

Cannot climb

Can climb two feet on each step with both hand support

Can climb two feet with on each step with one hand support

Can climb one feet at a time with support

Can climbing stairs better than in grade 4

1

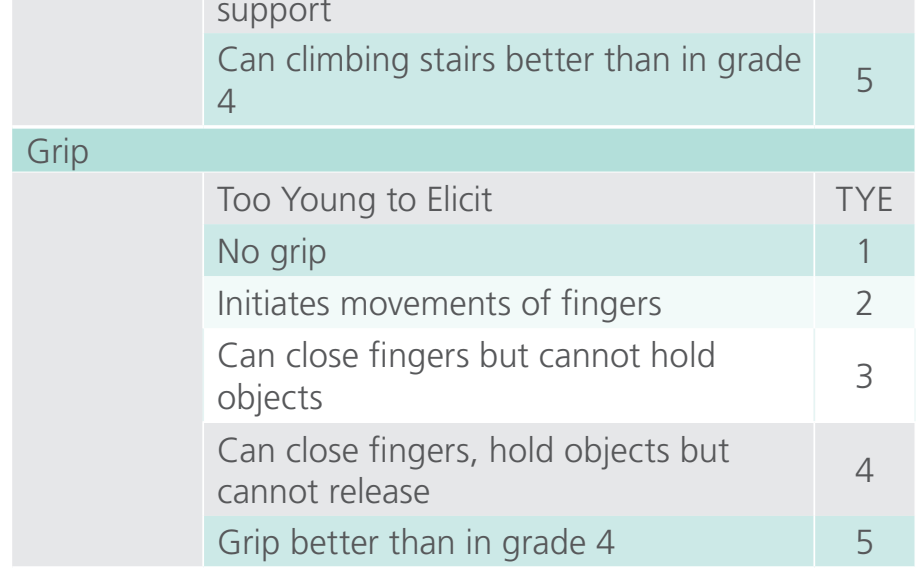


Each symptom is categorized into five ordinal grades $(1,2,3,4,5)$ in BAD $\rightarrow$ GOOD direction. These five numbers from $1 \rightarrow 5$ represents worst, bad, not so bad, good and normal, respectively. NFS is ordinal as it tells the condition of the case from Bad to Good. The spread of five grades of a symptom i.e., 1, 2, 3, 4 and 5 lies in a hypothetical categorical range of 0.5 and 5.5 , so as to keep the grades equidistant from each other and continuous. In probability-based studies, a range of $(-1,1)$ or at least the range of $(0,1)$ is required, so the grades are converted to respective numeric values. The ' $0.5^{\prime}$ and ' $5.5^{\prime}$ of hypothetical categorical range $(0.5,5.5)$ is considered as ' 0 ' and ' 1 ' of the $(0,1)$ numeric scale, respectively. The configuration can be used for one symptom and is now universal. For $Y_{n}=$ numeric score and $Y_{c}=$ categorical score, the relationship at any value of ' $\mathrm{X}$ ' will be $\frac{Y+0.166}{0.096}=x \quad \frac{Y+0.5}{0.5}$. The conversion of the grades is presented in Table 1. This layout can be used universally to convert five categorical grades (range; 0.5 to 5.5 ) to five numeric grades (range; 0 to 1$)$ or three categorical grades to three numeric grades (range; 0, 1) depending upon the symptoms of parameters assessed by NFS.

\section{Discussion}

Children with CP need to be assessed carefully to establish the intensity of impairment before initiating any therapy. Till date, it has been done using the following tools; GMFCS, MACS and BFMF. [4-6] GMFCS scoring system was developed by
Palsino and colleagues in 1997, later revised and expanded in 2007 to overcome its limitations. [4, 9] GMFCS classifies CP into five levels; I, II, III, IV and $\mathrm{V}$. The scores are ordinal and in the direction I (good) $\rightarrow \vee$ (bad) i.e. opposite to the direction of NFS which runs in direction 1 (bad) $\rightarrow 5$ (good). These levels differ from each other based on functional limitations and the need of assistive technology type such as walkers, canes, crutches and wheeled mobility by the children. GMFCS scoring is mainly aimed at determining the level which can reflect the patients' current limitations and abilities. [8]

GMFCS appears to be a broad classification symptom as the difference between Level I and Level II is not clearly recognizable. [8] In NFS, even the slightest improvement in the symptom is noted. Thus, evaluation of the patient's condition using NFS seems to be much more precise. The GMFCS scoring levels have also been described differently for children in several age ranges. [8] On the other hand, NFS scoring system is a single classification for the patients of all ages reducing the complexity of the evaluation system for physicians. GMFCS can only assess the patients aged upto. [10], whereas NFS can be used to assess the patients above this age limit.

As opposed to GMFCS which mainly assesses the ability of the patient to walk and stand, NFS is a broadened approach which can assess the ability to control head, balance the body, or walking. It can also assess the abilities related to sensory system such as feeling and controlling bladder and bowel

Table 1. Conversion table from categorical grades to numeric range for NFS.

\begin{tabular}{c|l|c|c|c|c|c|}
\multirow{2}{*}{$\begin{array}{c}\text { No. of } \\
\text { grades }\end{array}$} & Numeric & \multicolumn{5}{|c|}{ Categorical grades } \\
\cline { 2 - 8 } & & 1 & 2 & 3 & 4 & 0.89 \\
\hline \multirow{2}{*}{5} & Score & 0.122 & 0.310 & 0.500 & 0.690 & $0.759-1.00$ \\
\hline \multirow{2}{*}{3} & Range & $0-0.241$ & $0.241-0.379$ & $0.379-0.621$ & $0.621-0.759$ & - \\
& Score & 0.167 & 0.500 & 0.833 & - & - \\
\end{tabular}


excretion, hearing, and seeing and cognitive abilities like feeling hotness or coldness and understanding a "command".

To further illustrate the use of NFS, let us take a hypothetical example of a patient with $\mathrm{CP}$ who is assessed with both the scoring systems (NFS and GMFCS), before and after receiving therapy. NFS grading per symptom is presented in Table 2. Let us assume that a patient with $C P$ is placed in level 5 of GMFCS scoring system based on his

Table 2. A Hypothetical Example Showing NFS Grades of a Patient Before and After Therapy.

\begin{tabular}{|c|c|c|c|}
\hline Symptoms Before therapy & $\begin{array}{l}\text { NFS } \\
\text { Grades }\end{array}$ & Symptoms After therapy & $\begin{array}{l}\text { NFS } \\
\text { Grades }\end{array}$ \\
\hline Drooling & 1 & Drooling reduced to $1-2$ times a day & 5 \\
\hline Does not follow commands at all & 1 & Follow commands & 5 \\
\hline Does not smile & 1 & Smiles more congenitally & 5 \\
\hline Does not recognize anyone & 1 & Recognition is more intimate & 5 \\
\hline Eye contact absent & 1 & Eye contact is bolder & 5 \\
\hline Aggressive all the time & 1 & Aggression has reduced highly & 5 \\
\hline Does not speak & 1 & Able to speak many words but no sentences & 4 \\
\hline Indicate only basic things (wet, hunger and pain) & 2 & Able to indicate many words & 5 \\
\hline Fed with peg tubes & 1 & $\begin{array}{l}\text { Could be given liquids and solids with much less } \\
\text { difficulty }\end{array}$ & 5 \\
\hline Does not indicate for toilet & 1 & Indicate for bowel and bladder & 5 \\
\hline Totally dependent on his parents for daily living skills & 1 & Able to do daily living skills and complete them & 5 \\
\hline Defense mechanism absent according to the age & 1 & $\begin{array}{l}\text { Defense mechanism presented by anticipating } \\
\text { and without seeing stimulus }\end{array}$ & 4 \\
\hline Could swallow liquids & 2 & Able to swallow solids with much less difficulty & 5 \\
\hline $\begin{array}{l}\text { Constipation frequency is reported to be } 3 \text { times } \\
\text { a week }\end{array}$ & 2 & $\begin{array}{l}\text { Constipation frequency reduce to even less than } \\
\text { once a week }\end{array}$ & 4 \\
\hline Head control absent & 1 & Could complete head control with support & 5 \\
\hline Trunk control absent & 1 & Could hold trunk & 5 \\
\hline Could not initiate rolling & 1 & $\begin{array}{l}\text { Initiates, taking turn and could hold for more } \\
\text { than } 5 \text { minutes }\end{array}$ & 5 \\
\hline Not able to get into the position of crawling & 1 & Able to crawl & 5 \\
\hline Could not sit & 1 & Able to sit with much less trunk support & 5 \\
\hline Could not stand & 1 & Able to stand without chest support & 5 \\
\hline Could not walk & 1 & Able to walk & 5 \\
\hline Could not grip & 1 & Able to close fingers and hold objects & 5 \\
\hline Epilepsy & NAA & - & NAA \\
\hline Hearing & NAA & - & NAA \\
\hline Vision & NAA & - & NAA \\
\hline Breathing difficulty & NAA & - & NAA \\
\hline Kyphosis & NAA & - & NAA \\
\hline Scoliosis present & 1 & Scoliosis lessered & 5 \\
\hline Writing & TYI & - & TYI \\
\hline Mathematical skill & TYI & - & TYI \\
\hline I.T skills & TYI & Able to control mouse and discriminate sound & 3 \\
\hline Climbing stairs & TYI & Able to climb stairs without support & 5 \\
\hline Total & 26 & Total & 120 \\
\hline
\end{tabular}


functional limitations, according to which voluntary control over movements was limited, was unable to maintain trunk and head postures, motor function was limited, and he needed assistance for mobility. However, there were other symptoms in the patients that could not be accounted using GMFCS. The symptoms were drooling, not following commands at all, not smiling, inability to recognize anyone, absence of eye contact, aggressiveness, inability to speak, ability to indicate only basic things (wet, hunger and pain), feeding possible with only peg tubes, inability to indicate for toilet, totally dependent on his parents for daily living skills, absence of defense mechanism according to the age, could swallow liquids only, constipation (3 times a week), head control absent, trunk control absent, could not initiate rolling, not able to get into the position of crawling, could not write, scoliosis present, I.T skills absent, could not sit, stand, walk, climb stairs and grip. As per NFS system, the patient scored 26 before therapy calculated by adding the grades of the all symptoms which describes the patient's current state.

After receiving the therapy, the patient is again evaluated with NFS and GMFCS scoring system. The total NFS score after the therapy is 120 and the GMFCS score is 1. (Table 2) NFS score of 120 is calculated by adding the grades of individual symptoms to which the patient moved after the treatment. Improvement is noted in the symptoms including drooling, following commands, smiling, ability to recognize, eye contact, aggressiveness, ability to speak, ability to indicate, feeding, indicating for toilet, ability to do daily living skills, scoliosis lessened, defense mechanism developed, swallowing ability for solids, constipation frequency reduced, head and trunk control developed. The patient is also able to initiate rolling, able to crawl, developed I.T skills, able to sit, stand, walk, climb stairs and grip.

From this example, we can understand that GMFCS assesses the parameters broadly. In NFS, we graded parameters like commands, recognition, aggression, defense mechanism, constipation, ability to grip, breathing difficulty, feeding; which are not at all assessed individually in GMFCS. The other advantage of using NFS is that grades can be added or subtracted, thus can reveal even the slightest improvement in the patient. However, in GMFCS, the patient is graded to be in a single level that describes his/her present functional abilities. Our study poses a limitation in that NFS has only been used at our facility; however its wide use by other healthcare professionals in India and abroad is required to gather evidences signifying its use. The use of these numeric scores universally is recommended because they are pure numbers staying within the range of $(0,1)$, thus are compatible to all variables that distribute likewise including the probability distributions.

We have statistically validated the efficacy of human embryonic stem cells (hESCs) in patients with CP using NFS and results of this study will be presented in a different paper. Thus, NFS can be considered as a unique tool to assess the improvement in patients with CP. The NFS scoring system has only been used to evaluate the improvement in patients receiving hESC therapy. Further studies are needed to assess the improvement in CP patients receiving other treatments.

\section{Acknowledgement}

The authors acknowledge all the doctors, all staff and patients of the Nutech Mediworld. The authors also acknowledge Knowledge Isotopes Pvt. Ltd. (http://www.knowledgeisotopes.com) for the medical writing assistance.

\section{Funding}

There were no funding resources for this study. 


\section{Competing Interests}

The author confirms the absence of any competing interest.

\section{Abbreviations}

Cerebral palsy (CP), Gross Motor Function Classification System (GMFCS), the Manual Ability Classification System (MACS) and Bimanual Fine Function (BFMF), Nutech Functional Scores (NFS), not afflicted ailment (NAA), too young to elicit (TYE) and human embryonic stem cells (hESCs).

\section{References}

1. Tessier DW, Hefner JL, Newmeyer A (2014) Factors related to psychosocial quality of life for children with cerebral palsy. Int J Pediatr 2014: 6.

2. Centers for Disease Control and Prevention. Data and Statistics for Cerebral Palsy. Available http://www.cdc.gov/ncbddd/cp/ data.html. Accessed 19 December, 2014.

3. Centers for Disease Control and Prevention. Facts about Cerebral Palsy. Available http://www.cdc.gov/ncbddd/cp/facts.html. Accessed 27 Feburary, 2015.

4. Palisano R, Rosenbaum P, Walter S, Russell D, Wood E, Galuppi $B$ (1997) Development and reliability of a system to classify gross motor function in children with cerebral palsy. Developmental medicine and child neurology 39(4): 214-223.

5. Beckung E, Hagberg G (2000) Correlation between ICIDH handicap code and Gross Motor Function Classification System in children with cerebral palsy. Developmental medicine and child neurology 42(10): 669-673.

6. Eliasson AC, Krumlinde-Sundholm L, Rosblad B, Beckung E, Arner M, et al. (2006) The Manual Ability Classification System (MACS) for children with cerebral palsy: scale development and evidence of validity and reliability. Developmental medicine and child neurology 48(7): 549-554.

7. Palisano RJ, Cameron D, Rosenbaum PL, Walter SD, Russell D (2006) Stability of the gross motor function classification system. Developmental medicine and child neurology 48(6): 424-428.
8. CanChild. Centre for Childhood Disability Research. Gross Motor Function Classification System for Cerebral Palsy Available: http:// motorgrowth.canchild.ca/en/gmfcs/resources/gmfcs_english. pdf. Accessed 28 January, 2015.

9. Silva DB, Pfeifer LI, Funayama CA (2013) Gross Motor Function Classification System Expanded \& Revised (GMFCS E \& R): reliability between therapists and parents in Brazil. Braz J Phys Ther 17(5): 458-463.

10. Palisano RJ, Rosenbaum P, Bartlett D, Livingston MH (2008) Content validity of the expanded and revised Gross Motor Function Classification System. Developmental medicine and child neurology 50(10): 744-750.

\section{Comment on this article:}

\section{8 in $8+S$}

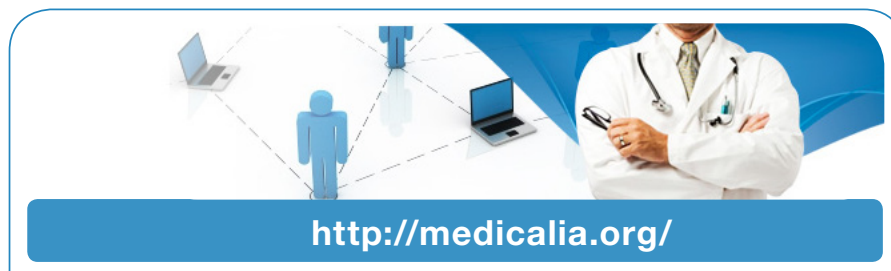

Where Doctors exchange clinical experiences, review their cases and share clinical knowledge. You can also access lots of medical publications for free. Join Now!

\section{Publish with iMedPub}

http://www.imed.pub

International Archives of Medicine is an open access journal publishing articles encompassing all aspects of medical science and clinical practice. IAM is considered a megajournal with independent sections on all areas of medicine. IAM is a really international journal with authors and board members from all around the world. The journal is widely indexed and classified Q1 in category Medicine. 